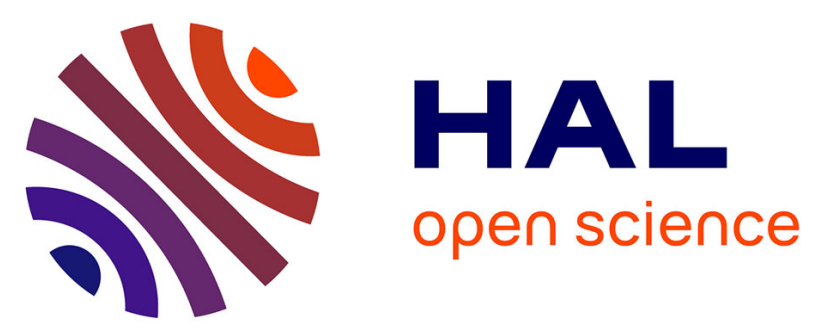

\title{
The defect structure of CdTe
}

\author{
F.A. Kröger
}

\section{To cite this version:}

F.A. Kröger. The defect structure of CdTe. Revue de Physique Appliquée, 1977, 12 (2), pp.205-210. 10.1051/rphysap:01977001202020500 . jpa-00244144

\section{HAL Id: jpa-00244144 https://hal.science/jpa-00244144}

Submitted on 1 Jan 1977

HAL is a multi-disciplinary open access archive for the deposit and dissemination of scientific research documents, whether they are published or not. The documents may come from teaching and research institutions in France or abroad, or from public or private research centers.
L'archive ouverte pluridisciplinaire HAL, est destinée au dépôt et à la diffusion de documents scientifiques de niveau recherche, publiés ou non, émanant des établissements d'enseignement et de recherche français ou étrangers, des laboratoires publics ou privés. 


\title{
THE DEFECT STRUCTURE OF CdTe (*)
}

\author{
F. A. KRÖGER \\ David Packard Professor of Electrical Engineering \\ Departments of Materials Science and Electrical Engineering \\ University of Southern California, Los Angeles, California 90007, U. S. A.
}

\begin{abstract}
Résumé. - Dans cet article de revue on s'intéresse aux défauts physiques existant dans le tellurure de cadmium, l'accent étant mis sur les conditions produisant des cristaux de haute résistivité.

Abstract. - Evidence concerning the defect structure of CdTe is reviewed with particular reference to the conditions producing high resistivity material.
\end{abstract}

1. Introduction. - Recently, results from self-diffusion experiments [1] and of high-temperature Hall effect measurements on pure and donor-doped CdTe $[2,3]$ have been used to arrive at the defect structure of CdTe. The structure found is rather complicated, involving both interstitial defects and vacancies, each ionized to various degrees. The species believed to be present are $\mathrm{Cd}_{\mathrm{i}}{ }_{\mathrm{i}}, \mathrm{V}_{\mathrm{Te}}^{\bullet}, \mathrm{V}_{\mathrm{Cd}}^{\prime \prime}, \mathrm{V}_{\mathrm{Cd}}^{\prime}, \mathrm{Te}_{\mathrm{i}}^{\prime}$, $\mathrm{Te}_{\mathrm{i}}^{x}$.

In the following section we shall try to determine to what extent the proposed defect structure can be trusted and what aspects are open to doubt. This will be done by reviewing the evidence on which the analysis was based. A second point that deserves consideration concerns the techniques used to make CdTe of high resistivity as used as $\gamma$ detectors and as windows for high energy $\mathrm{CO}_{2}$ lasers. This will be done in section 3 .

2. The defect structure of CdTe and diffusion coefficients of individual defects as determined from selfdiffusion data and high-temperature hall data. Established with a reasonable degree of certainty are the following points:

2.1 Hall effect measurements on undoped $\mathrm{CdTe}$ single crystals at high temperatures where the crystals are in equilibrium with a vapor of known cadmium pressure $[2,3]$ show that the crystals are n-type with $c_{\mathrm{e}} \propto p_{\mathrm{Cd}}^{1 / 3}$. The conductivity of such crystals at high temperature shows a similar dependence [4-6] : $\sigma_{\mathrm{e}} \propto p_{\mathrm{Cd}}^{1 / 3}$. This indicates that we are dealing with doubly ionized native donors which may be either $\mathrm{Cd}_{\mathbf{i}} \ddot{\text { or }} V_{\mathrm{Te}}$.

$\left(^{*}\right)$ This work was supported by the Defense Advanced Research Project Agency under Contract F-19628-72-C-0275, Project 2055.
2.2 Cd tracer diffusion measurements on undoped CdTe at high $p_{\mathrm{Cd}}$ show a dependence for the tracer diffusion coefficient $D_{\mathrm{Cd}}^{*} \propto p_{\mathrm{Cd}}^{1 / n}$ with $n \approx 5[1]$.

$$
D_{\mathrm{Cd}}^{*}=\sum_{j} f_{j} D_{j}[j],
$$

$f_{j}$ being the correlation coefficient for diffusion of the tracer by the species $j, D_{j}$ being the diffusion coefficient of $j$, and $[j]$ its concentration expressed as a site fraction. The dependence found is weaker than expected for $\mathrm{Cd}_{\mathrm{i}} \cdot \mathrm{i}^{\bullet}$ and can be accounted for by the presence of this species only if there are contributions to $D_{\mathrm{Cd}}^{*}$ by species with a concentration varying $\propto p_{\mathrm{Cd}}^{-1 / n}$ as well as one by a species, the concentration of which is independent of $p_{\mathrm{Cd}}$. Additional evidence for the presence of the latter will be presented later. The observation of $D_{\mathrm{Cd}}^{*}$ increasing with $p_{\mathrm{Cd}}$ is in agreement with a preliminary result by de Nobel [7], but is in disagreement with statements by Whelan and Shaw [8] and Borsenberger and Stevenson [9] who both report $D_{\mathrm{Cd}}^{*}$ to be independent of $p_{\mathrm{Cd}}$. The results of the former authors scatter too much to reveal the weak dependence mentioned above. Inspection of the data points by Borsenberger and Stevenson shows, however, that their results allow a weak $p_{\text {Cd }}$ dependence. Therefore, we believe that the conclusion reached above is correct.

2.3 Te tracer self-diffusion measurements on undoped CdTe at high $p_{\mathrm{Cd}}$ are in line with a contribution to $D_{\mathrm{Te}}^{*} \propto p_{\mathrm{Cd}}^{1 / 3}$ on top of a contribution $\propto p_{\mathrm{Cd}}^{-1}$ (see 2.4), thus supporting the presence of $V_{\mathrm{Te}}^{\ddot{*}}$ as a tellurium transporting species at high $p_{\mathrm{Cd}}$.

2.4 Te tracer self-diffusion in pure CdTe at low $p_{\mathrm{Cd}}$ is proportional to $p_{\mathrm{Cd}}^{-1}$, indicating uncharged $\mathrm{Te}_{\mathrm{i}}^{\boldsymbol{x}}$ as the tellurium transporting species under these conditions $[9,10]$. Since $\mathrm{Te}_{\mathrm{i}}^{x}$ is neutral, its concentration should not be affected by doping. This has not been confirmed for CdTe, but it has been confirmed for the diffusion of sulphur tracer by $\mathrm{S}_{\mathrm{i}}^{x}$ in $\mathrm{CdS}$ at low $p_{\mathrm{Cd}}$ [11]. 
2.5 The dependence of the $\mathrm{Cd}$ vacancy concentration on $p_{\mathrm{Cd}}$ and [In $\dot{C}_{\mathrm{Cd}}$ ] in CdTe : In at medium to high $p_{\mathrm{Cd}}$ where $\left[\mathrm{In}_{\dot{C}_{d}}\right] \approx\left[e^{\prime}\right]$ depends on the charge of the vacancy :

$$
\begin{aligned}
& {\left[A_{\mathrm{n}}^{\prime}\right] \propto[\mathrm{In}]^{-1} p_{\mathrm{Cd}}^{-1}} \\
& {\left[A_{\mathrm{n}}^{\prime \prime}\right] \propto[\mathrm{In}]^{-2} p_{\mathrm{Cd}}^{-1} .}
\end{aligned}
$$

At low $p_{\mathrm{Cd}}$, the concentrations of $A_{\mathbf{n}}^{\prime}$ and $A_{\mathbf{n}}^{\prime \prime}$ have values fitting the neutrality condition

$$
\left[\operatorname{In}_{\mathbf{C d}}^{\cdot}\right] \approx\left[A_{\mathbf{n}}^{\prime}\right]+2\left[A_{\mathbf{n}}^{\prime \prime}\right]+\left[e^{\prime}\right] .
$$

Here also $\left[A_{\mathbf{n}}^{\prime}\right]$ and $\left[A_{\mathbf{n}}^{\prime \prime}\right]$ depend in a different way on $p_{\mathrm{Cd}}$. In general, therefore, the ratio between the concentrations of $A_{\mathrm{n}}^{\prime \prime}$ and $A_{\mathrm{n}}^{\prime}$ vary with $p_{\mathrm{Cd}}$ as well as [In $\dot{\mathrm{Cd}}_{\mathrm{d}}$ ]. Analysis of the shape of $\mathrm{Cd}$ self-diffusion isotherms for CdTe with different amounts of indium shows that at the point where $\left[e^{\prime}\right]=\left[h^{\circ}\right],\left[A_{\mathrm{n}}^{\prime}\right] /\left[A_{\mathrm{n}}^{\prime \prime}\right]=8$ at $700{ }^{\circ} \mathrm{C}, 5$ at $800{ }^{\circ} \mathrm{C}$ and 2.8 at $900{ }^{\circ} \mathrm{C}$, independent of the ratio in which $V_{\mathrm{Cd}}$ and $\mathrm{Te}_{\mathrm{i}}$ contribute to $A_{\mathrm{n}}^{\prime}$ and $A_{\mathrm{n}}^{\prime \prime}$. This fixes the isotherms for $A_{\mathrm{n}}^{\prime}$ and $A_{\mathrm{n}}^{\prime \prime}$ but leaves the ratio $r^{\prime}=\left[V_{\mathrm{Cd}}^{\prime}\right] /\left[\mathrm{Te}_{\mathrm{i}}^{\prime}\right]$ and $r^{\prime \prime}=\left[V_{\mathrm{Cd}}^{\prime \prime}\right] /\left[\mathrm{Te}_{\mathrm{i}}^{\prime \prime}\right]$ undetermined. Note that since $V_{\mathrm{Cd}}^{\prime}$ and $\mathrm{Te}_{\mathrm{i}}^{\prime}$ and $V_{\mathrm{Cd}}^{\prime \prime}$ and $\mathrm{Te}_{\mathrm{i}}^{\prime \prime}$ depend pairwise in the same manner on $p_{\mathrm{Cd}}$ and [In], $r^{\prime}$ and $r^{\prime \prime}$ are constants dependent on temperature only.

2.6 Cd tracer self-diffusion measurements of donordoped CdTe show a complicated behavior : at high $p_{\mathrm{Cd}}, D_{\mathrm{Cd}}^{*}$ as $f([$ donor]) shows a decrease at low donor concentrations followed by an increase at high donor concentrations (Fig. 1). At low $p_{\mathrm{Cd}}, D_{\mathrm{Cd}}^{*}$ increases with

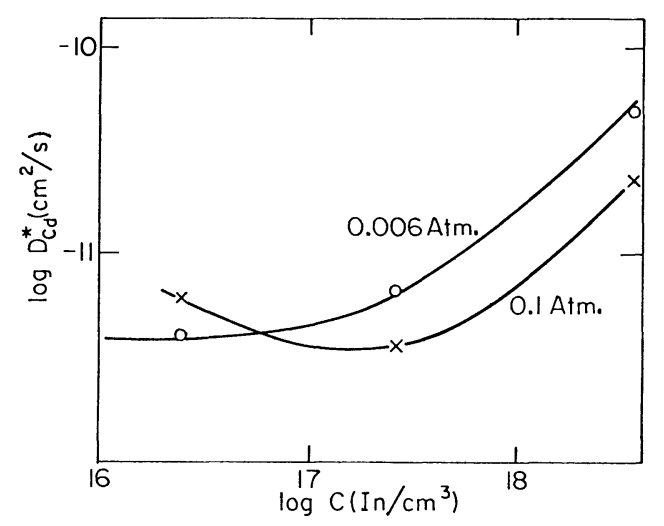

FIG. 1. $-D_{\mathrm{Cd}}^{*}$ as a function of $[\mathrm{In}]$ at $700^{\circ} \mathrm{C}$ at $p_{\mathrm{Cd}}=1 \mathrm{~atm}$ and $p_{\mathrm{Cd}}=0.006 \mathrm{~atm}$.

increasing donor concentration at all donor concentrations, but less than proportional. The initial decrease at high $p_{\mathrm{Cd}}$ is due to the suppression of $\mathrm{Cd}_{i} \cdot{ }^{\cdot}$ in the presence of In $\dot{C}_{\mathbf{C d}}$. From

$$
\mathrm{Cd}(\mathrm{g}) \rightarrow \mathrm{Cd}_{\mathrm{i}}^{\cdot \bullet}+2 e^{\prime}
$$

it follows that $\left[\mathrm{Cd}_{\mathrm{Cd}}\right] \propto p_{\mathrm{Cd}} /\left[e^{\prime}\right]^{2}$. Therefore, an increase of $\left[e^{\prime}\right] \approx\left[\mathrm{In}_{\mathrm{Cd}}^{\cdot}\right]$ gives a decrease in $\left[\mathrm{Cd}_{\mathrm{i}} \ddot{\bullet}^{\circ}\right]$. The increa- se at high $p_{\mathrm{Cd}}$ at higher [ $\left.\operatorname{In}_{\dot{C}_{d}}\right]$ is due to the increase in the concentrations of $V_{\mathbf{C d}}^{\prime \prime}$ and $V_{\mathbf{C d}}^{\prime}$ :

$$
\begin{gathered}
\mathrm{Cd}_{\mathrm{Cd}}^{x} \rightarrow V_{\mathrm{Cd}}^{n^{\prime}}-n e^{\prime}+\mathrm{Cd}(\mathrm{g}) \\
{\left[V_{\mathrm{Cd}}^{n^{\prime}}\right] \propto\left[e^{\prime}\right]^{n} / p_{\mathrm{Cd}} \propto\left[\mathrm{In}_{\mathrm{Cd}}\right]^{n} / p_{\mathrm{Cd}} .}
\end{gathered}
$$

At low $p_{\mathrm{Cd}}$ where $\left[\mathrm{In}_{\mathrm{Cd}}^{\cdot}\right] \approx\left[V_{\mathrm{Cd}}^{\prime}\right]+\left[\mathrm{Te}_{\mathrm{i}}^{\prime}\right]+2\left[V_{\mathrm{Cd}}^{\prime \prime}\right]$, $D_{\mathrm{Cd}}^{*}$ increases right from the start because here $\left[\mathrm{Cd}_{\mathrm{i}}^{*}\right]$. is so small that an initial decrease cannot be observed.

2.7 As we saw earlier, the dependence of $D_{\mathrm{Cd}}^{*}$ on $p_{\mathrm{Cd}}$ in CdTe : In has to be explained through

$$
D_{\mathrm{Cd}}^{*}=\sum_{j} D_{\mathrm{Cd}, j}^{*}=\sum_{j} f_{j} D_{j}[j],
$$

$j$ being the species $V_{\mathrm{Cd}}^{\prime}, V_{\mathrm{Cd}}^{\prime \prime}$ and possibly $\left(\operatorname{In}_{\mathrm{Cd}} V_{\mathrm{Cd}}\right)^{\prime}$. We know already from 2.5 the values of $\left[A_{n}^{\prime}\right]$ and $\left[A_{\mathrm{n}}^{\prime \prime}\right]$ at each $p_{\mathrm{Cd}}$ and $T$. In isotherms, the contributions of the various species to $D_{\mathrm{Cd}}^{*}$ are given by

$$
\begin{aligned}
& D_{V_{\text {Cd }}^{\prime}}^{*}=\left\{r^{\prime} f_{V_{C_{d}}^{\prime}} D_{V_{C_{d}}^{\prime}} /\left(1+r^{\prime}\right)\right\}\left[A_{n}^{\prime}\right] \\
& D_{V_{C_{d}}^{\prime \prime}}=\left\{r^{\prime \prime} f_{V_{C_{d}}^{\prime \prime}} D_{V_{C d}^{\prime \prime}} /\left(1+r^{\prime \prime}\right)\right\}\left[A_{n}^{\prime \prime}\right]
\end{aligned}
$$

with the $f$ factors constant, and the $D^{\prime} \mathrm{s}$ and $r^{\prime}$ and $r^{\prime \prime}$ functions of temperature only. So far the $D^{\prime} \mathrm{s}$ as well as $r^{\prime}$ and $r^{\prime \prime}$ are unknown. Here we come to the more doubtful parts of the analysis.

Points Open to Question. - 1. Determination of the parameters $r^{\prime}$ and $r^{\prime \prime}$ is possible if the electronic energy levels of the various species are known. The positions of several local levels are known, but their assignment to particular species is uncertain. Table I summarizes the positions of various donor and acceptor levels and the species they are believed to be due to. There is no general agreement on these assignments. The assignments we have believed to be correct and which were used in the analysis are underlined in table I.

With these level assignments one finds $r^{\prime} \approx 1$ and $r^{\prime \prime} \approx \infty$, i. e., $V_{\mathrm{Cd}}^{\prime}$ and $\mathrm{Te}_{\mathrm{i}}^{\prime}$ contribute almost equally to $A_{\mathrm{n}}^{\prime}$, whereas $A_{\mathrm{n}}^{\prime \prime} \approx V_{\mathrm{Cd}}^{\prime \prime}$. Using these values of $r$ it was tried to find values of $D_{\mathrm{Cd}, j}^{*}$ fitting the data in such a manner that each $D_{\mathrm{Cd}, j}^{*}$ depends exponentially on inverse temperature. It is found that this is possible only if there is a contribution $D_{j}$ that depends exponentially on $T^{-1}$ but is independent of [In] and $p_{\mathrm{Cd}}$. The latter conclusion was already arrived at in 2.1). The requirement that individual $D_{\mathrm{Cd}}^{*}=f_{j} D_{j}[j]$ should depend exponentially on $T^{-1}$ is somewhat too restrictive. For although it is correct for $D_{j}$, it is correct for $[j]$ only if $j$ is either a minority species or if $[j]$ is constant as is the case for $V_{\mathrm{Cd}}^{\prime}$ if $\left[V_{\mathrm{Cd}}^{\prime}\right]=\left[\mathrm{In}_{\mathrm{Cd}}^{\cdot}\right]$. It is not correct if various species $j$ are equally close to dominance, e. g., $\left[V_{\mathrm{Cd}}^{\prime}\right] \approx\left[\mathrm{Te}_{\mathrm{i}}^{\prime}\right] \approx \frac{1}{2}\left[\mathrm{In}_{\mathrm{Cd}}^{\cdot}\right]$, with the ratio $r^{\prime}=\left[V_{\mathrm{Cd}}^{\prime}\right] /\left[\mathrm{Te}_{\mathrm{i}}^{\prime}\right]$ varying with temperature. However, even in this case the error is only small. Therefore, the error introduced in the analysis by the requirement of linearity cannot be appreciable. 
TABLE I

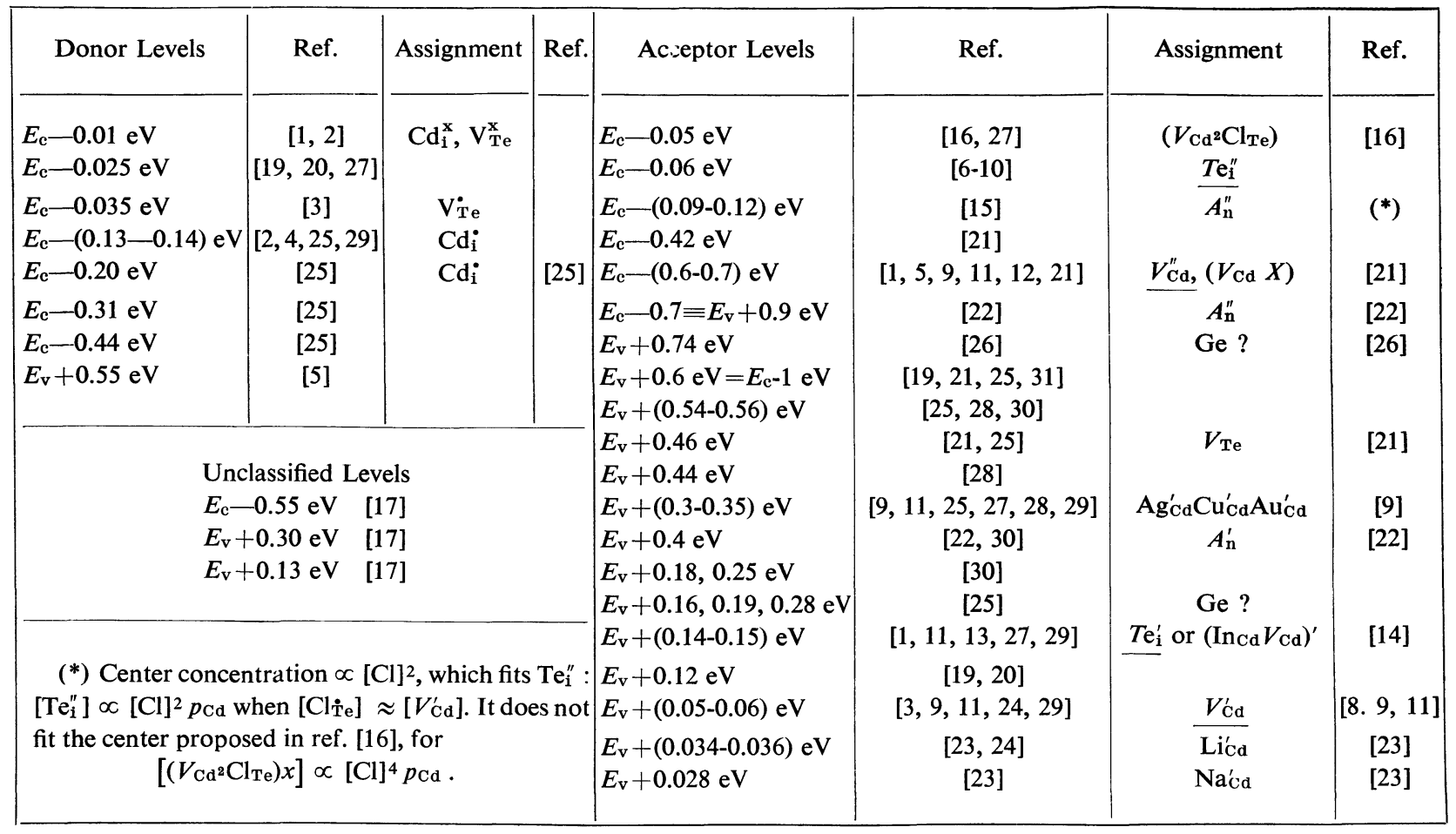

\section{References to table I}

[1] De Nobel, D., Philips Res. Rept. 14 (1959) 430.

[2] Rud, Yu V. and SAnin, K. V., Sov. Phys. Semicond. 5 (1971) 244.

[3] Ivanov, V. S., StopachinskiI, V. B. and Chapnin, V. A., Sov. Phys. Semicond. 5 (1971) 83.

[4] Whelan, R. C. and Shaw. D., Phys. Stat. Sol. 29 (1968) 145.

[5] Agrinskaya, N. V., Arkad'eva E. N. and Matveev, O. A., Sov. Phys. Semicond. 4 (1970) 306.

[6] Halsted, R. E. and Segall, B., Phys. Rev. Lett. 10 (1963) 392.

[7] Lorenz, M. R. and Woodbury, H. H., Phys. Rev. Lett. 10 (1963) 215.

[8] Lorenz, M. R., Aven, M. and Woodbury, H. H., Phys. Rev. 132 (1963) 143.

[9] Lorenz, M. R. and Segall, B., Phys. Lett. 7 (1963) 18 ; Lorenz, M. R., Segall, B. and Woodbury, H. H., Phys. Rev. 134 (1963) 751.

[10] Abramov, A. A., Vavilov, V. S. and Vodop'yanov, I. K., Sov. Phys. Semicond. 4 (1970) 219.

[11] Vul, B. M., Vavilov, V. S., IVanov, V. S., StopachinskiI, V. P. and Chapnin, V. A., Sov. Phys. Semicond. 4 (1970), 52 ; 6 (1973) 1255.

[12] Zanio, K., Akutagawa, W. M. and Kikuchi, R., J. Appl. Phys. 39 (1968) 2818.

[13] Agrinskaya, N. V., Arkad'eva, E. N. and Matveev, O. A., Sov. Phys. Semicond. 4 (1970) 347.

[14] Agrinskaya, N. V., Arkad'eva, E. N. and Matveev, O. A., Sov. Phys. Semicond. 5 (1971) 767.

[15] Agrinskaya, N. V., Alekseenko, M. V., Arkad'eva, E. N., Matveev, O. A. and Prokof'ev, J. V., Sov. Phys. Semicond. 9 (1975) 208.

[16] Bell, R. O., Solid State Commun. 16 (1975) 913.

[17] Charager, S., Muller, J. C., Stuck, R. and Siffert, P., Phys. Stat. Sol. 31(a) (1975) 247.

[18] Woodbury, H. H., Proc. 7th Intern. Conf. Physics of Semiconductors, Paris, 1964, vol. 3, Radiation Damage in Semiconductors (Dunod, Paris, Akad. Press. New York) 1965, p. 179.

REVUE DE PHYSIQUe APPLIQUÉE. - T. 12, No 2, FÉVRIER 1977
[19] Arkad'eva, E. N., Maslova, L. V., Matveev, O. A., Prokof'ev, S. V., Ryfkin, S. M. and Kusainov, A. Kh., Sov. Phys. Dokl. 20 (1975) 211.

[20] Alekseenko, M. V., Arkad'eva, E. N., Kisilenko, V. S., Maslova, L. V., Matveev, O. A., Prokof'ev, S. V., Ryfkin, S. M. and Kusainov, A. Kh., Sov. Phys. Semicond. 8 (1974) 351.

[21] Caillot, M., Intern. Symposium on $\gamma$ Counters and X-ray Detection, Strasbourg, June 21, 1971 (P. Siffert and A. Cornet editors) paper XIII.

[22] Vul, B. M., Vavilov, V. S., Ivanov, I. S., Stopachinsky, V. B., ibid., paper XI ;

Chapnin, V. A., Sov. Phys. Semicond. 3 (1969) 481 ;

Sokolova, A. A., Vavilov, V. S., Plotnikov, A. F. and Chapnin, V. A., Sov. Phys. Semicond. 3 (1969) 612 ; Vul, B. M., Vavilov, V. S., Ivanov, V. S., StopaChinskiI, V. B. and Chapnin, V. A., Sov. Phys. Semicond. 2 (1973) 1255.

[23] Crowder, B. L. and Hammer, W. L., Phys. Rev. 150 (1966) 541.

[24] Gu, T., Kitahara, T., KawaKami, K. and Sakaguchi, T., J. Appl. Phys. 46 (1975) 1223.

[25] Zayachkoskit, V. P., Saviskit, A. V., Nikonyuk, E. S., Kitsa, M. S. and Matlak, V. V., Sov. Phys. Semicond. 8 (1974) 675.

[26] Matlak, V. V., Nikonyuk, E. S., Savitskil, A. V. and Tovstyuk, K. D., Sov. Phys. Semicond. 6 (1973) 1760.

[27] Canali, C., Ottaviani, G., Bell, R. O. and Wald, F. V., J. Phys. Chem. Solids 35 (1974) 1405.

[28] Kydd, R. F. and Bryant, F. J., Phys. Stat. Sol. 23(a) (1974) K 49.

[29] Gippius, A. A., Panossian, J. R. and Chapnin, V. A., Phys. Stat. Sol. 21(a) (1974) 753.

[30] Martin, G. M., Fogarassy, E. and Fabre, E., J. Appl. Phys. 47 (1976) 264.

[31] Nikonyuk, E. S., Parfenyuk, O. A., Matlak, V. V., Tovstyuk, K. D. and SAVITSKII, A. V., Sov. Phys. Semicond. 9 (1975) 840. 
A contribution to $D_{\mathrm{Cd}}^{*}$ that is independent of $p_{\mathrm{Cd}}$ may be explained by species $V_{\mathrm{Cd}}^{\prime \prime}, V_{\mathrm{Cd}}^{\prime}$ or $\mathrm{Cd}_{\mathbf{i}}^{*}$ formed by Schottky or Frenkel disorder. However, these would be charged and therefore their concentration would be modified by doping with indium, leading to a dependence on [In] which is contrary to what was observed. The only possibility left is a contribution by an uncharged associate, $\left(\mathrm{Cd}_{\mathrm{i}} V_{\mathrm{Cd}}\right)^{x}$. This can be seen as the transition state of the simplest ring mechanism of diffusion: interchange of two neighboring $\mathrm{Cd}$ atoms.

2. In ref. [3] a division of $D_{\mathbf{n}}^{\cdot \ddot{n}}$ into $V_{\mathrm{Te}}^{\ddot{*}}$ and $\mathrm{Cd}_{\mathrm{i}}^{\ddot{*}}$ was made on the basis of the consideration that the negative dependence of $c_{\mathrm{e}}$ on temperature observed in undoped CdTe after cooling can only be explained

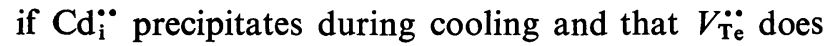
not, and if the former species is dominant at high $T$, the latter at low $T$. We are not completely certain that this conclusion is correct. It seems possible that this negative $T$ dependence can arise from the fact that the intrinsic carrier concentration $K_{\mathbf{i}}^{1 / 2}$ has a stronger temperature dependence than the constant $K_{\text {CdI }}^{1 / 3}$ governing the establishment of a deviation from stoichiometry. The results obtained for the contributions of the various diffusion mechanisms to the $\mathrm{Cd}$ tracer diffusion coefficients of undoped CdTe and CdTe : $3.6 \times 10^{18} \mathrm{In} \mathrm{cm}^{-3}$ at $700{ }^{\circ} \mathrm{C}$ are shown in figure 2 .

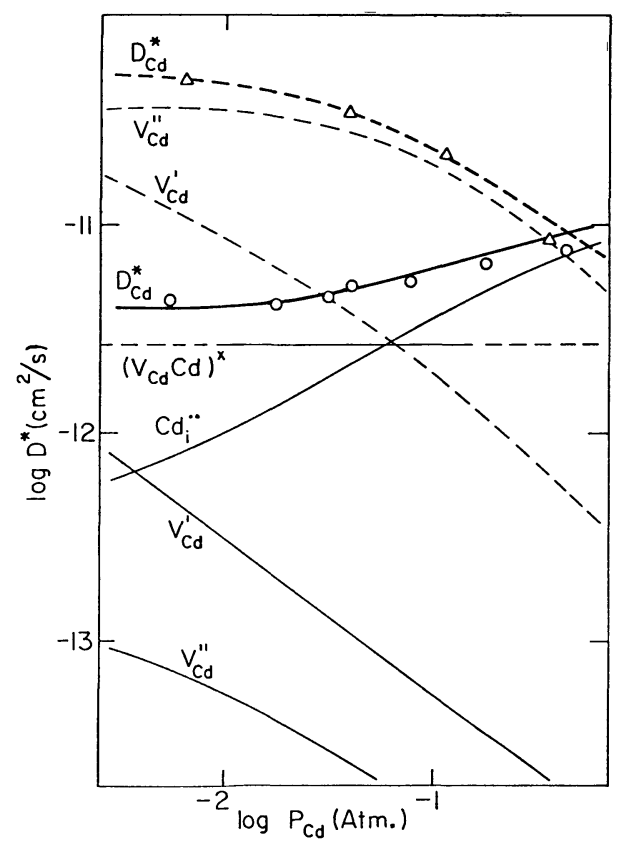

FIG. 2. $-D_{\mathrm{Cd}}^{*}$ of undoped CdTe and CdTe $: 3.6 \times 10^{18} \mathrm{In}^{-3}$ at $700{ }^{\circ} \mathrm{C}$ and contributions to it by various diffusion mechanisms $D_{\mathrm{Cd}, j}^{*}=f_{j} D_{j}[j]$.

The temperature dependence of such contributions for $\mathrm{Cd}$ tracer diffusion and $\mathrm{Te}$ tracer diffusion in undoped CdTe are shown in figure 3. With the values of $r^{\prime}, r^{\prime \prime}$, and $\left[\mathrm{Te}^{x}\right] /\left[\mathrm{Te}_{\mathrm{i}}^{\prime}\right]$ based on assumed level positions and $\left[A_{n}^{\prime}\right]$ and $\left[A_{n}^{\prime \prime}\right]$ as given above corresponding to the

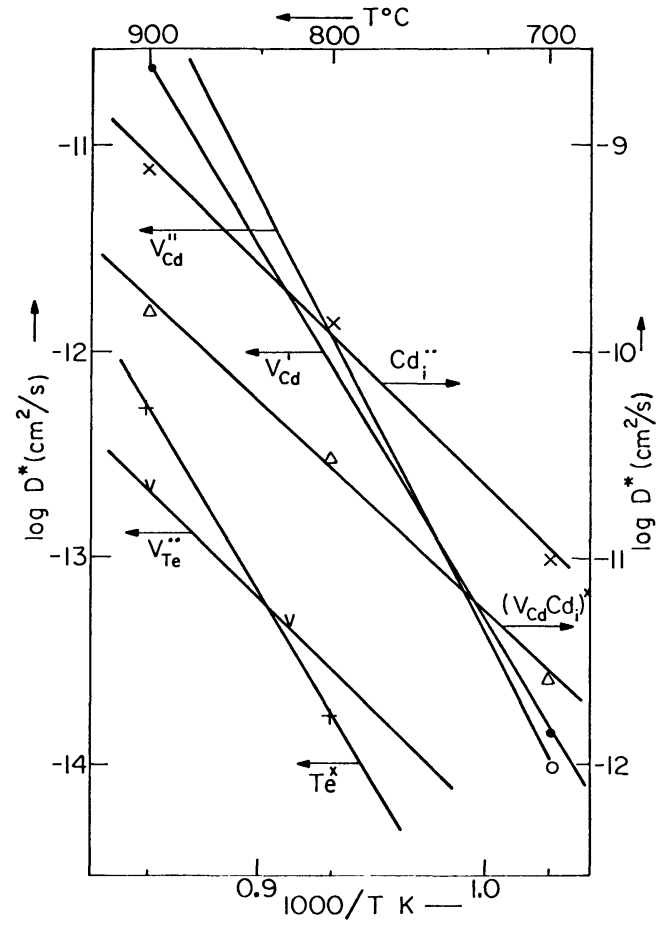

Fig. 3. - Temperature dependence of contributions by various defects to $D_{\mathrm{Cd}, j}^{*}$ and $D_{\mathrm{Te}, j}^{*}$ in undoped CdTe at $p_{\mathrm{Cd}}=1 \mathrm{~atm}$.

parameters for the constants of defect formation as presented in table III of ref. [3], we can calculate the concentrations of all species as $f\left(p_{\mathrm{Cd}}, T\right.$, [In]). Combination with the individual contributions to $D_{\mathrm{Cd}}^{*}$ and $D_{\mathrm{Te}}^{*}$ as presented in table I of ref. [1] then allows us to determine expressions for defect diffusion coefficients $D_{j}(T)$.

Such results were presented in table II of ref. [1]. However, it was pointed out to us that several of the parameters as given in this table are in error. Corrected values are presented in table II.

\section{TABLE II}

Parameters for the diffusion constants of individual defects

\begin{tabular}{ccc}
\multicolumn{3}{c}{$D_{j}=D_{j}^{0} \exp \left(-H_{j}^{\mathrm{eV}} / k T\right)$} \\
Defect $j$ & $D_{j}^{0}\left(\mathrm{~cm}^{2} \mathrm{~s}^{-1}\right)$ & $H_{j}(\mathrm{eV})$ \\
- & - & - \\
$\mathrm{Cd}_{\mathrm{i}}^{. *}$ & $29.4 \frac{\times}{!} 1.35\left(^{*}\right)$ & $1.23 \pm 0.02$ \\
$V_{\mathrm{Te}}^{.0}$ & $30 \frac{\times}{\vdots} 1.25$ & $1.91 \pm 0.04$ \\
$V_{\mathrm{Cd}}^{\prime}$ & 380 & 1.65 \\
$V_{\mathrm{Cd}}^{\prime \prime}$ & $2.24 \times 10^{4} \frac{\times}{:} 1.7$ & $2.09 \pm 0.07$ \\
$\mathrm{Te}_{\mathrm{i}}^{x}$ & $0.66 \frac{\times}{:} 1.6$ & $0.77 \pm 0.07$
\end{tabular}

${ }^{*}$ ) This notation for the error limit on $D_{j}^{0}$ means that $D_{j}^{0}$ lies between $1.35 D_{j}^{0}$ and $D_{j}^{0} / 1.35$. 
If any of the assumptions recognized as doubtful would be changed, this would change the defect formation constants of table III, ref. [3], which in turn would cause a change in the contributions by various defects to $D_{\mathrm{Cd}}^{*}$ and in the expressions for $D_{j}$ as given above.

One necessary change we are aware of at this stage concerns the expression for $K_{\mathrm{i}}$ as used in the analysis. The expression given in table III of ref. [3] gives a value of $K_{\mathrm{i}}$ at $900^{\circ} \mathrm{C}$ which is slightly too large and leads for pure CdTe to $\left[e^{\prime}\right]_{900} \propto p_{\mathrm{Cd}}^{1 / n}$ with $n \gg 3$. Use of $K_{\mathrm{i}}=1.48 \times 10^{-14} T^{3} \exp (-1.32 \mathrm{eV} / k T)$ atom $f r{ }^{2} \approx 3.76 \times 10^{-4} \exp (-1.60 \mathrm{eV} / k T)$ atom $f r^{2}$ as found by Smith [2] is to be preferred.

3. Preparation of high resistance material. - As found by de Nobel [7] reasonably pure material shows n-type conductivity after annealing at $700-900^{\circ} \mathrm{C}$ at high $p_{\mathrm{Cd}}$, and p-type conductivity after annealing at low $p_{\mathrm{Cd}}$ with a fairly sharp transition at some intermediate $p_{\mathrm{Cd}}$. At this transition point the material is usually inhomogeneous, some sections being n-type, other sections being p-type. We recently found the same behavior for material doped with $5 \times 10^{16} \mathrm{~cm}^{-3} \mathrm{Cl}$, donors, presumably compensated by an equal concentration of acceptor impurities [12]. It is also possible that most of the chlorine had precipitated removing the corresponding native defects and/or acceptor impurities (self-purification [13]).

The explanation put forward by de Nobel was that in undoped or compensated material, almost no levels are present in the center of the gap at which the Fermi level can be fixed. The slightest change of $p_{\mathrm{Cd}}$ or temperature causes the substance to change from n-type with a high to p-type with a low Fermi level. To get a material with its Fermi level stable at a mid-gap position, it is necessary to introduce species with levels near center gap. High resistance material obtained by donor doping combined with annealing below a critical cadmium pressure was believed to arise in this manner : the donor doping creates electrons at high $p_{\mathrm{Cd}}$ but ionic defects such as $V_{\mathrm{Cd}}^{\prime}$ and $V_{\mathrm{Cd}}^{\prime \prime}$ at low $p_{\mathrm{Cd}}$. If $V_{\mathrm{Cd}}^{\prime \prime}$ has a level close to mid-gap as assumed, $V_{\mathrm{Cd}}^{\prime}$ will act as an effective electron trap, and $V_{\mathrm{Cd}}^{\prime \prime}$ as an effective hole trap, thus causing a wide region of $p_{\mathrm{Cd}}$ and $T$ where the Fermi level is close to mid-gap. Yet, even in undoped CdTe $V_{\mathrm{Cd}}^{\prime}$ and $V_{\mathrm{Cd}}^{\prime \prime}$ are formed as a result of atomic disorder and deviation from stoichiometry. If precipitation of these species during cooling can be prevented, it should be possible to make even undoped CdTe of high resistance.

It is possible that the need for donor doping is due primarily to the need for avoiding acceptor doping, the latter reducing the concentrations of $V_{\mathrm{Cd}}^{\prime}$ and $V_{\mathrm{Cd}}^{\prime \prime}$. Positively charged defects such as $\mathrm{Cd}_{\mathbf{i}}^{*}, V_{\mathrm{Te}}^{\cdot}, \mathrm{Cd}_{\mathbf{i}}{ }^{\bullet}$ and $V_{\mathrm{Te}}$, the concentration of which are increased by acceptor doping, are ineffective as electron or hole traps because their levels are too close to the conduction band.

In various papers it is claimed that high resistance material can be made from undoped CdTe, the most recent one being that by Triboulet et al. [14]. However, this material was not really pure. It contained a donor (Al) at a concentration of the order $10^{15}-10^{16} \mathrm{~cm}^{-3}$. In addition, it contained carbon at a concentration of $10^{18} \mathrm{~cm}^{-3}$. Even if the concentration of $\mathrm{Al}$ would be too low to be effective through the formation of $V_{\mathrm{Cd}}$, one should still consider a possible role of $\mathrm{C}$. Observation of high resistance in material containing another type of four valent atom, Ge, $[15,16]$ with an energy level at $E_{\mathrm{v}}+0.74 \mathrm{eV}$ suggests that $\mathrm{C}$ may well be active. In deciding the mechanism by which high resistance is achieved it should be realized that the mechanism of stabilizing the Fermi level at mid-gap, though always involving deep levels, need not always involve the levels of $V_{\mathrm{Cd}}$. As in GaAs which is made semi-insulating by transition elements [17, 19], in particular chromium [20-22], the levels involved may be due to the dopant itself. We ourselves have made CdTe- $10^{17} \mathrm{Cr} \mathrm{cm}^{-3}$ which had a hole concentration of $2 \times 10^{12} \mathrm{~cm}^{-3}$ [23]. The energy level responsible for the high resistance of the Ge doped material may be a Ge-level, with stabilization of the Fermi level at that level by self-compensation of $\mathrm{Ge}_{\mathrm{Cd}}$ donors by $\mathrm{Ge}_{\mathrm{Te}}$ acceptors. It is likely that a systematic study involving other dopants will turn up other species able to make $\mathrm{CdTe}$ of high resistivity.

\section{References}

[1] Chern, S. S. and Kröger, F. A., J. Solid State Chem. 14 (1975) 44.

[2] SмITH, F. T. J., Met. Trans. 1 (1970) 617.

[3] Chern, S. S., Vydyanath, H. R. and Kröger, F. A., $J$. Solid State Chem. 14 (1975) 33.

[4] Whelan, R. C. and Shaw, D., Phys. Stat. Sol. 29 (1968) 145.

[5] Zanio, K., Appl. Phys. Lett. 15 (1969) 260.

[6] Rud, Yu. V. and Sanin, K. V., Sov. Phys. Semicond. 5 (1971) 244.

[7] De Nobel, D., Philips Res. Rep. 14 (1959) 361, 430.

[8] Whelan, R. C. and Shaw, D., in II-VI Semiconducting Compounds (D. G. Thomas, Ed.) (Benjamin, New York) 1907, p. 451.
[9] Borsenberger, P. J. and Stevenson, D. A., J. Phys. Chem. Solids 29 (1968) 1277.

[10] Woodbury, H. H. and Hall, R. B., Phys. Rev. 157 (1967) 641.

[11] Kumar, V. and Kröger, F. A., J. Sol. Stat. Chem. 3 (1971) 387.

[12] KRöger, F. A. and Selim, F. A., in IR Window Studies, AFCRL-TR-74-0268, Defense Advanced Research Project Agency Contract No. F 19628-72-C-0275, Order No. 2055, Quarterly Tech. Report No. 7, March 1974, p. 25.

[13] Matveev, O. A., Arkadeva, E. N., Goncharov, L. A., Sov. Phys. Dokl. 20 (1975) 220. 
[14] Triboulet, R., Marfaing, Y., Cornet, A. and Siffert, P., J. Appl. Phys. 45 (1974) 2759.

[15] Matlak, V. V., Nikonyuk, E. S., Savitskit, A. V. and Tovstyuk, K. D., Sov. Phys. Semicond. 6 (1973) 1760.

[16] ZayachkoskiI, V. P., SavitskiI, A. V., Nikonyuk, E. S., Krtsa, M. S. and Matlak, V. V., Sov. Phys. Semicond. 8 (1974) 675.

[19] Plescewicz, W., Phys. Stat. Sol. 16(a) (1973) 485.

[20] Oтsubo, M. and Miki, H., Japan. J. Appl. Phys. 13 (1974) 1655.

[21] Peka, G. P., Brodovoi, V. A., Zernov, S. L. and Minets, L. Z., Phys. Stat. Sol. 29(a) (1975) 47.

[22] Brodoi, V. A. and Derikov, N. Z., Sov. Phys. Semicond. 7 (1973) 958.

[17] Grobe, E. and Salow, H., Z. Angew. Phys. 32 (1972) 381.

[18] Bekmuryakov, M. F. and Murygin, V. I., Sov. Phys. Semicond. 7 (1973) 55.

[23] Kröger, F. A. and Selim, F. A., Proceedings of the Conference on High-Power Infrared Laser Window Materials, Las Vegas, Nevada, Nov. 1975. 